\title{
La carrera de un capellán de honor de Palacio en la crisis del Antiguo Régimen (1783-1827)
}

\author{
Juan Carlos SaAvedra Zapater
}

\section{RESUMEN}

La presente comunicación intenta acercarnos al estudio de los capellanes de honor de la Real Capilla como grupo social y élite de poder. La Capilla real, parte integrante de la Casa Real como institución en sí misma,

sufre con la evolución de los acontecimientos del final del Antiguo Régimen, las transformaciones propias tanto en las cuestiones económicas como en las funcionales. Tomando como referencia la vida y carrera de Antonio llarraza vemos el proceso que un individuo debe de llevar a cabo para acceder al honor de ser capelán real: su carrera, trayectoria profesional y relaciones sociales y de parentesco, así como es utilizado este empleo para acceder a más altos cargos

Palabras claves: Casa Real, Capilla Real, capellanes reales

\section{SUMMARY}

The present paper is an aproximation to the study of the Royal Chaplans of the Royal Chapel as a social group and elite of power. The Royal Chapel, a department within the whole Royal Hause as an institution in itself, suffers with the evolution of events during the end of the Ancien Régime, the proper transformations and changes, in economical aspects as in its rule. Taking the life and carrer of Antonio llarraza as a reference, we can analize the procces that a person has to realize in order to achive the honor of a royal chaplancy: his professional charges, his studios and personal relationships, familiar and social as this job is used to get more important charges.

Keyword: Royal Hause, Royal Chapel, Royal Chaplans. 


\section{INTRODUCCIÓN}

El presente artículo intenta abordar el estudio de la carrera de un Capellán de Honor dentro de la Real Capilla, enmarcado en las transformaciones que se producen a finales del Antiguo Régimen. La Real Capilla es uno de los elementos institucionales -los restantes serían la Casa del Rey, la Casa de la Reina, la Real Caballeriza y, con menor entidad, la Casa de Caballeros Pajes- que componen el centro de poder cortesano por excelencia: la Casa Real. De aquí la importancia que tiene el capellán de honor como un cargo directamente relacionado con la familia real e inmerso en uno de los grupos de poder dentro de palacio. Para estudiar el tema que nos ocupa analizaremos, por un lado, la Capilla Real a fines del siglo XVIII y comienzos del XIX; por otra parte, el proceso que se sigue para que un individuo entre a engrosar las filas del banco de capellanes de honor, estudiando ai mismo tiempo su origen geográfico y social (linaje y trayectoria profesional de la familia), sus relaciones de parentesco y amistad, así como sus estudios y su carrera eclesiástica antes de acceder a este honor. Por último se analizará cuál fue la evolución de la carrera de un Capellán una vez dentro de la Capilla y cómo ésta sirve de importante trampolín para la obtención de mayores cargos y honores.

\section{LA CAPILLA REAL A FINALES DEL SIGLO XVIII}

La Capilla Real es el núcleo eclesiástico que organiza, en torno a la Real Familia, todos los aspectos relacionados con el culto divino. A la jerarquía de la Capilla -léase el Patriarca de Indias- le corresponde la jurisdicción en materia espiritual de todo el ámbito del Palacio: la familia Real, los cortesanos y criados de las Casas Reales y los ministros propiamente dichos de la Capilla Real y, en la época que nos ocupa, también la de los cortesanos y criados que se trasladen o incluso que residan de forma permanente en los Reales Sitios, dado que a partir del Concordato de 1753 la Capilla Real se ha erigido en parroquia y el Patriarca, siempre celoso de su jurisdicción, ejerce ésta en todo su «territorio parroquial», tanto en sentido sacramental como judicial para los ministros eclesiásticos 1 .

1 Sobre el Concordato de 1753, ver R. S. LAMADRID, El Concordato español de 1753 segün los documentos originales de su negociación, Jerez de la Frontera,1937. Para una visión de la Iglesia española en la segunda mitad del siglo XVIII, W. J. CALLAHAN, Iglesia, poder y sociedad en España, 1750-1874, Madrid, 1989. 
La Capilla Real, como todas las instituciones dependientes de la Casa Real, estuvo sometida a un continuo intento de reforma y acondicionamiento a los nuevos tiempos desde la llegada del primer Borbón, Felipe $V$, en 1700. Baste recordar que la primera planta que se realiza de los ministros de la Capilla, tanto eclesiásticos como músicos, es de 17012 . Son variadas, como casi siempre, las motivaciones que llevan a reformar una institución, aunque en el caso que nos ocupa podemos básicamente establecer dos: reforzar su jurisdicción y sanear su economía. En cuanto a las circunstancias jurisdiccionales, los problemas se arrastraban desde antiguo. Podemos resumir que la base de esta conflictividad era, por un lado, el enfrentamiento entre el Patriarca como máxima autoridad de la Capilla Real y el Mayordomo de Palacio, su correspondiente en las Casas Reales, por cuestiones relacionadas con la administración de los recursos asignados a la Capilla Real y el nombramiento de cargos 3; por otro lado, se aprecia una pugna, soterrada pero constante, entre el Patriarca y el Arzobispo de Santiago, en quien realmente recaía el cargo de Capellán y Limosnero Mayor, actuando el primero, en consecuencia, en sustitución suya, dado que el Arzobispo de Santiago tenía la obligación de residir en su Diócesis y, por tanto no podía desempeñar las funciones inherentes al empleo de Capellán Mayor; finalmente, respecto de la jurisdicción canónica y sacramental sobre los ministros de la Capilla y feligreses de ella, el conflicto surge al enfrentarse al Patriarca el Arzobispo de Toledo, quien reclama los derechos de jurisdicción territorial sobre el territorio que "supuestamente" abarca la Capilla, al no constituir parroquia, lo que quedará solucionado a raíz del Concordato de 1753, ya que durante las conversaciones para conseguir la redacción definitiva de éste, el Patriarca presiona al Rey para que envíe órdenes a favor de la conveniencia de erigir la Capilla en Parroquia, lo que finalmente se consigue por Bula $\mathrm{Pa}$ pal de 27 de junio de 17534.

Las motivaciones económicas nacen de una circunstancia obvia: Felipe $\mathrm{V}$ comienza su reinado teniendo que hacer frente a una guerra que

2 J. C .SaAvedra Zapater y J. A. Sánchez Belén, "La hacienda de la Real Capilla durante el reinado de Felipe V", en La Herencia de Borgoña. La hacienda de las Reales Casas durante el reinado de Felipe $V$, Madrid. 1998, pp. 121-155

3 Varios ejemplos de este enfrentamiento en J. A, SánCHez Belén y J. C. SAAVEdra ZaPaTer, "La Capilla Real de Felipe V durante la Guerra de Sucesión", Homenaje a Antonio de Bethencourt y Massieu, Las Palmas de Gran Canaria, 1995, t. III, pp. 367-401.

4 Archivo General de Simancas (AGS), Gracia y Justicia (G y J), leg. 931. Breve de Nuestro Muy S. P. Benedicto XIV a favor de la Capilla Real, dado en 27 de junio de 1753. Sobre las protestas del Arzobispo de Toledo, Archivo General de Palacio, Reinado de Fernando VI, Caja $93 / 11$. 
deja vacías las arcas de la corona, lo que le obliga a imponer rigurosos presupuestos en todos los departamentos de la administración y, por descontado, de la Casa Real a fin de contener el despilfarro y el descontrol en muchos de los pagos. Acabada la Guerra de Sucesión las dificultades financieras no concluyen. Las aventuras militares que tienen lugar después de Utrecht con Alberoni y luego con ocasión de la Guerra de Sucesión de Polonia en 1734 y la Guerra de Sucesión de Austria en $1746^{5}$ acaban por esquilmar el erario, dejándose de abonar los salarios del personal de las Casas Reales, cuyos gastos se habían disparado entre 1729 y 1733 con la boda del príncipe de Asturias, la Jornada a Andalucia y el viaje del infante don Carlos a Italia ${ }^{6}$. Así se explica que en 1739 se intenta acometer la reforma de las Casas Reales, incluida la Capilla Real, empresa que, sin embargo, se pospone y que sólo se retomará en 1749 durante el ministerio del marqués de la Ensenada 7 . Será, no obstante, en 1756, cuando se perfile de una manera definitiva la independencia económica del clero de la Capilla Real y, en definitiva, del Mayordomo Mayor de Palacio, ya que el Patriarca consigue aplicar a este colectivo una parte de las mesadas eciesiásticas para retribuir con puntualidad a los capellanes de honor por sus oficios, satisfaciendo, aunque no por completo, sus quejas acerca de carecer de una dotación fija para el pago de sus distribuciones ${ }^{8}$, y asignar además gajes a un número determinado de capellanes por el ejercicio de ciertos empleos. De hecho, las quejas y petición de reembolso de las cantidades adeudadas, no ya a los capellanes, sino a todos los criados de la Capilla Real será una constante durante todo el

5 A. Bethencour Massieu, Relaciones de España bajo Felipe V. Del Tratado de Sevilla a la guerra con Inglaterra (1729-1739), Alicante, 1998.

6 C. Gómez-Centurión Jiménez y J. A. SÁnchez Belén, «Lá hacienda de la Casa del Rey durante el reinado de Felipe V", en La herencia de Borgoña. La hacienda de las Reales Casas durante el reinado de Felipe V, Madrid, 1998, pp. 11-120. Sobre la Jornada a Badajoz y Sevilla, J. JURAdO SÁNCHEZ, «Los viajes reales en la Edad Moderna: la visita de Felipe V y su Corte a Badajoz y Andalucía (1729-1733)m, Andalucia Moderna. Actas del II Congreso de Historia de Andalucia, Córdoba, 1995, pp. 541-558, y A. G. MÁRQuez Reinoso, Sevilla, "Ciudad y Corte" (1729-1733), Sevilla, 1994.

7 C. Gómez-Centurión Jiménez, «La reforma de las Casas Reales del marqués de la Ensenada", Cuadernos de Historia Moderna, 20, 1998, pp. 59-83. Para la política de Ensenada, J. L. GOMEZ URDÁNEZ, El proyecto reformista de Ensenada, Lleida, 1996. En la misma corriente se encontraba José de Carvajal y Lancaster, como así se desprende de su Testamento Político. Ver al respecto, J. M. Delgado BARRADo, José de Carvajal y Lancaster. Testamento político o idea de un gobierno católico (1745), Córdoba, 1999.

8 Al respecto ver J. C. SaAvedra Zapater y J. A. Sánchez Belén, «Los capellanes de honor de la Capilla real (1701-1757): Aproximación a su estudiom, en E. MARTínez Ruiz y V. SUÁREz GRimón (Eds), Iglesia y sociedad en el Antiguo Régimen, Las Palmas de Gran canaria, 1994, pp. 177-186. 
siglo, de tal manera que se llegan a abonar salarios, mercedes y pensiones con hasta más de veinte años de retraso ${ }^{9}$.

\section{EL SISTEMA DE ACCESO DE UN CAPELLÁN DE HONOR. LAS PRUEBAS DE LIMPIEZA Y DE NOBLEZA DE SANGRE. EL INTERROGATORIO}

Las plazas de Capellán de honor se cubren mediante un proceso establecido. Ante todo se requiere que los aspirantes sean licenciados en teología o cánones y, por tanto, que hayan cursado estudios universitarios, según se exige en las constituciones de la Real Capilla, además de estar en posesión de rentas saneadas, dado que tendrán que sufragar de su bolsillo los gastos de todo el proceso de limpieza. Observado este requisito, el primer paso de este proceso es la presentación al monarca de los individuos más a propósito, por parte del Patriarca, para ocupar las capellanías vacantes y que, salvo contadas excepciones, el Rey suele aprobar. A veces, sin embargo, es el rey quien directamente concede el título de Capellán a algún individuo que se haya destacado por servicios a la Corona. Durante la Guerra de Sucesión, en 1713, Felipe V otorga la Capellanía de Honor a José Ciurana y Francisco Camps, por su ayuda en la manutención de las guarniciones felipistas que combatían contra el Archiduque en Cataluña durante los disturbios ocurridos en aquel reino ${ }^{10}$. En 1741, el monarca concede esta merced a Juan Bautista Vaneti, capellán de la compañía española de Guardias de Corps, por haber servido al infante D. Felipe, futuro Duque de Parma, en la campaña de Italia ${ }^{11}$. Y no son casos aislados, pues la documentación consultada contiene otras muchas concesiones en esta línea a lo largo del siglo XVIII.

Aceptada la propuesta de nombramiento, el siguiente paso es la notificación que se da al pretendiente para que presente su genealogía en la Secretaría de Cámara del Patriarca (en muchos casos se conserva en el expediente la carta enviada por el secretario del Patriarca al interesado para el efecto). Una vez presentada ésta el Secretario escribe al Receptor de la Capilla para que requiera del candidato el depósito acostumbrado

9 J. C .SaAvedra Zapater y J. A. Sánchez Belén, "La hacienda de la Real Capilla durante el reinado de Felipe V", en La Herencia de Borgoña. La hacienda de las Reales Casas durante el reinado de Felipe $V$, Madrid.1998, pp. 121-155.

10 Archivo General de Palacio (AGP), Expedientes Personales (EP), Caja 239/31 y Felipe V, $\operatorname{leg} 380$.

11 AGP, EP, Caja 16521/5. 
para la realización de las pruebas, lo que también se observaba en las pruebas de acceso a los Colegios Mayores o a los puestos del Santo Oficio. Este depósito en la primera mitad del siglo XVIII suele ser, "según costumbre", de unos 924 reales -de ello quedan bastantes notificaciones incluidas en los distintos expedientes de Capellanes-, aunque esta cantidad era a menudo superada, como lo confirma el hecho de que los diferentes recibís que el Secretario, el Notario y el Pesquisidor dan como justificante de haber percibido las cantidades que les corresponden por el proceso suman en conjunto cerca de los 1500 reales, sin que la documentación nos aclare en absoluto este desfase. En otras ocasiones, por el contrario, los gastos parecen ser inferiores al depósito realizado, ya que algunos capellanes de honor, una vez terminados los trámites y conseguido el nombramiento, solicitan a la Secretaría de la Cámara se les devuelva el sobrante de las costas del proceso Para la segunda mitad de la centuria la cuantía del depósito se había casi triplicado, según se deduce del realizado por José Benito de llarraza Ladrón de Guevara, que efectúa un desembolso de unos cien doblones o, lo que es lo mismo, de unos cuatro mil reales de plata 12 .

Efectuado el depósito, el Patriarca expide entonces la Comisión para el capellán informante dando las instrucciones precisas de cómo se ha de llevar a cabo la información de acuerdo con lo establecido en las Constituciones de 1757 13. Así, en la Comisión dada en 1783 por D. Antonio Sentmanat y Cartella al capellán de honor Juan Antonio García Iñigo para las pruebas de Santiago Antonio de llarraza, se dice: “Nos el Patriarca, por la presente cometemos nuestras veces plenariamente a D. Capellán de Honor de S. M. para que pasando a los lugares y domicilios de naturaleza que constan de la genealogía...haga información de testigos fidedignos, los mas ancianos del lugar, para la naturaleza, limpieza y legitimidad, por ambas líneas, y de la vida y costumbres de D... y arreglándose en todo al capítulo XXV de las Constituciones de la Capilla" 14 . Es interesante resaltar que el informante ha de pasar a los domicilios de naturaleza del pretendiente, algo que no se había estado haciendo en el siglo XVIII, pues se tomaba interrogatorio a testigos que estuvieran en la Corte y que conocieran en diferente grado al pretendiente y a su familia, con lo que viene a recuperarse la práctica que se había observado, con excep-

12 AGP, EP, Caja 7829/6.

13 AGP, Sección Administrativa, leg 1133. Constituciones de la Real Capilla de los Reyes Católicos, 1757.

14 AGP, EP, Caja 7790/5. Comisión del Patriarca a Juan Antonio García Iñigo, San Ildefonso, 6 de octubre de 1783. 
ciones -es el caso de capellanes de honor originarios de los virreinatos americanos e italianos-, hasta finales del siglo XVII.

El informante asignado, que deberá tener una antigüedad como capellán de honor de al menos dos años y que no podrá renunciar al nombramiento, bajo sanción de ser apartado de la Real Capilla durante un año sin poder recibir los emolumentos que le correspondan ${ }^{15}$, tras aceptar su nombramiento procede a desplazarse al lugar de origen del pretendiente, cuyo itinerario, desde 1757, queda fijado por una junta de cuatro capellanes de honor nombrada a tal efecto por el Patriarca ${ }^{16}$. Llegado a su destino, comienza el interrogatorio de diferentes testigos, cuyo número oscila entre catorce y veinticuatro -dependiendo de las épocas-, si bien desde mediados del siglo XVIII se estipula que al menos deberán ser examinados doce testigos no presentados por el pretendiente, costumbre que también se había relajado durante los primeros cincuenta años del siglo 17. En el caso de Santiago Antonio llarraza son trece los individuos interrogados, algunos, como en Añiriz, son elegidos "de entre la clase de labradores ... prefiriendo a los que por su entereza, ancianidad y nobleza son mas respetables", y otros, por el contrario, pertenecen a la nobleza y al clero. Así, los testigos interrogados en Vitoria son José Manuel de Esquivel, marqués de Legarda, caballero de la Llave Dorada y subdelegado de las rentas reales, Agustín de Mendivil, abogado de los Reales Consejos y Roque de Gámiz, beneficiado de la universidad de Vitoria y cura párroco de San Vicente, $y$, en Mondragón, Manuel Antonio de Aguirre, beneficiado de la parroquial de dicha villa, Vicario Foráneo de la Vicaria del partido de Léniz, Manuel José Gaitán de Ayala y José Ángel Aranguren, de quienes, sin embargo, no sabemos su profesión o pertenencia social, no sabiendo muy bien si ello obedece a que su alta posición hacía innecesario que tuviesen que dejar constancia de este hecho o bien a que su origen o situación social, nada prestigiosa, no requería constancia alguna. Este detalle de los testigos que no declaran sus ocupaciones será una constante en todos los procesos de limpieza de sangre a lo largo de todo el siglo XVIII ${ }^{18}$.

El informante dispone del instrumento principal para llevar a cabo su cometido, que es el interrogatorio de preguntas adjunto que se le entrega

15 AGP, Sección Administrativa, leg 1133. Constituciones de la Real Capilla de los Reyes Católicos, 1757, artículo 25.

16 Ibidem, artículo 26.

17 Ibidem, artículo 25.

18 AGP, EP, Caja $7790 / 5$. 
firmado de la mano del Patriarca y refrendado del secretario de la Capilla, que se somete a su vez al capítulo XXV de las Constituciones de 1757 y que consta de ocho preguntas relativas a la legitimidad del pretendiente y de sus padres y abuelos, así como a la nobleza, limpieza de sangre, vida y costumbres del candidato y de la mayor cantidad posible de sus ascendientes. El pesquisidor tiene además capacidad para "compeler con castigos y censuras a los testigos" en caso de que incurrieran en quebrantamiento del juramento bajo el cual prestan su declaración, con potestad para imponerles "penas y gravámenes convenientes e incluso implorar el auxilio del brazo secular» 19.

Acabado el interrogatorio de los testigos, que puede tener lugar en varias poblaciones en el caso de Santiago Antonio de llarraza se interroga a tres vecinos de Ariñiz, seis de Vitoria, tres del lugar de Castillo y cuatro de Mondragón-, el informante pasa a las iglesias de los lugares de origen para comprobar en los libros parroquiales la legitimidad a través de las partidas de bautismo, casamiento y defunciones, amén de otros muchos instrumentos que puedan aportarse como certificados de fallecimiento, poderes otorgados, herencias, cartas de Ejecutoria, testamentos, testimonios de nombramientos para ejercer cargos públicos, etc. A veces, por negligencia de los curas párrocos, no aparecen anotadas determinadas partidas, lo que obliga al informante a recurrir a otros medios para confirmar la legitimidad de tal o cual otro familiar. En el caso de Santiago Antonio de llarraza, el informante, que había aceptado y jurado cumplir la comisión para la que había sido nombrado en la Granja de San Ildefonso el ocho de octubre de 1783 , se encuentra con que en los libros parroquiales de Ariñiz, en la provincia de Álava, donde había nacido el pretendiente, no aparece la partida de bautismo de la madre, por lo que se traslada a Vitoria donde todo parece indicar que fue bautizada. Sin embargo, en la iglesia parroquial de San Pedro de esa localidad tampoco aparece, afirmando el cura párroco que el incidente posiblemente se deba a que no fue anotado el bautismo por omisión del anterior párroco. Es entonces cuando el informante decide interrogar a tres testigos que puedan determinar si la madre de Santiago Antonio de Ilarraza era legítima hija de Francisco de Oro Umendia y de Inés de Lete. Para Francisco Ascenio de Gámiz, beneficiado de la Universidad de Vitoria y cura parroquial de la iglesia de San Pedro, quien además hace la certificación final, no cabe la menor duda de esa legitimidad, toda vez

19 AGP, EP, Caja 7790/5. Comisión del Patriarca a Juan Antonio García Iñigo, San Ildefonso, 6 de octubre de 1783. 
que sabe fue bautizada en dicha parroquial por el párroco Martín de Armentia hacia los años 1720 y que este cura omitió inscribir la partida de bautismo, como había hecho con muchas otras partidas de bautismo, defunciones y casamientos. Pone como ejemplo el que en el libro parroquial sí estén inscritos los bautismos de los hermanos mayores y menores de la interesada. Los otros dos testigos, Pedro de Santa María e Ignacio de Arrazola Oñate, declaran básicamente lo mismo, con lo que el informante, a la vista de estos testimonios, decide dar por buena la legitimidad de la madre de Santiago Antonio de llarraza. Tampoco la abuela paterna, María de Villodas, nacida el 8 de septiembre de 1659 en Añiriz, fue inscrita en los libros de bautismo de la parroquia, aunque esta omisión fue subsanada, a petición de su esposo, Juan de llarraza, por el obispo de Calahorra quien el 16 de noviembre de 1693 ordena que sea anotada en los referidos libros tras la diligencia de interrogar a varios testigos que dieran fe de su legitimidad.

Concluido el interrogatorio de los testigos y la comprobación de la genealogía del pretendiente, el juez informante levanta Auto de cesación de las pruebas y redacta el informe final, que suele ser favorable, enviando toda la documentación del proceso en un sobre lacrado al receptor de la Capilla, Melchor Borruel, para que, conforme a las constituciones de la Real Capilla, ésta se reúna para su dar su aprobación. En el ejemplo que estamos estudiando, Juan Antonio García Iñigo elabora su informe de conclusiones en Mondragón el 29 de Octubre de 1783, al cabo de once días de trabajo -habia llegado a Añiriz el 18 del mismo mes-, siendo recibido en Palacio el 5 de diciembre de 1783.

Una vez que el proceso está en poder del Patriarca el secretario de la Capilla Real, de acuerdo con sus instrucciones, convoca una Junta de capellanes de honor para que examine todos y cada uno de los instrumentos que componen el expediente, presidida por el Patriarca o, en su ausencia, por la persona en la que delegue. Normalmente, entre la recepción de los documentos y su examen por la Junta apenas transcurren uno o dos días, pero no sucede esto con el expediente de Santiago Antonio de llarraza, puesto que la Junta, reunida como es habitual en la residencia del Patriarca, no celebra su sesión hasta el 10 de marzo de 1784, integrada en esta ocasión por el Receptor, Melchor Borruel (quien también estuvo en la comisión que aprobó las informaciones para Capellán de honor de José Benito de llarraza, hermano de Santiago Antonio de llarraza), Gaspar Salza, frey José Cornejo, José Isasi, Luis Martínez Toledano, Antonio Mosquera, Diego Colina, Agustín del Campo y Pablo José Salinero, quien actúa como secretario. 
Si todo está en regla, la Junta aprueba finalmente las informaciones en su totalidad, como sucede con el expediente de Santiago Antonio de Ilarraza: «Según previenen las constituciones, y estando como están conducentes en todas sus partes y con arreglo a los estatutos de la Real Capilla, uniformemente las ha aprobado." Cumplida esta diligencia, el Secretario del Patriarca comunica al rey la resolución de la Junta y, por tanto, que el pretendiente a la capellanía de honor reúne los requisitos exigidos para formar parte de la misma, tras lo cual el monarca da la orden, a través del Mayordomo Mayor, para que se haga el asiento correspondiente en los libros del Grefier. El último paso será el Juramento y toma de posesión en manos del Juez o Receptor de la Capilla por parte del pretendiente.

\section{SOCIOLOGIA DE LOS CAPELLANES DE HONOR. NOBLEZA MEDIA Y BURÓCRATAS}

¿Cuál es el estrato social de los capellanes de honor a finales del siglo XVIII? Exceptuando a los capellanes del Banco de las Ordenes Militares, que son todos caballeros de un hábito y, por tanto, de probada nobleza, el origen social de los capellanes del Banco de Castilla es más variado, por mucho que los testigos interrogados aseguren que sus ascendientes son de nobleza probada. El perfil de la mayoría se puede decir que es similar al de Santiago Antonio de llarraza y Oro. Nacido en el lugar de Ariñiz el 25 de julio de 1755, donde es bautizado el día siguiente en la iglesia parroquial de dicho lugar, pertenece a una familia de la nobleza hidalga vasconavarra, aunque esta nobleza haya sido litigada en la Chancillería de Valladolid, pues algunos testigos declaran en el proceso que han visto las Cartas de Ejecutoria de Hidalguía de la familia, que están en poder de los familiares del pretendiente, lo que ratifica a su vez el juez que interviene en las averiguaciones en su informe final cuando afirma haber examinado esos documentos -la presentación de cartas de Ejecutoria durante el proceso de informaciones es algo muy común en este tipo de expedientes-: "devolví las cartas ejecutorias a la parte interesada después que las hube estudiado detenidamente...» 20.

Su padre, José de llarraza, nacido en el mismo lugar el 13 de marzo de 1701 y su abuelo paterno, Juan de llarraza, nacido en el lugar de Castillo el 20 de octubre de 1663, fueron, según los testigos, procuradores

20 A.GP, EP, Caja 7790/5. Informe de Juan Antonio García Iñigo, 29 de octubre de 1783. 
síndicos generales de la provincia de Alava, lo que les confería el honor de tener asiento, voz y voto en las Juntas Generales de la Provincia, como otros muchos personajes vasco-navarros que alcanzan lustre, renombre, cargos y fortunas en el siglo XVIII 21. El padre, uno de los seis diputados de la Junta Particular de la Provincia, elegido con otros cinco comisionados para recibir a la Infanta de Francia, Duquesa de Parma, en su viaje a España acompañada de su hija 22 , fue además gobernador de la jurisdicción y tierra del Duque del Infantado. En este sentido continúan la tradición familiar, ya que varios testigos aseguran que sus ascendientes habian ya ocupado cargos públicos en sus lugares de origen en el siglo XVII.

A esta posición privilegiada dentro del gobierno político de la Provincia de Álava se suma la adquirida a través del matrimonio. Juan de Villodas, bisabuelo paterno de Santiago Antonio de llarraza, estuvo casado con Catalina de Crispijana y Mendoza, cuyo hermano, Andrés de Crispijana y Mendoza, fue Capitán de los ejércitos y contador mayor del ejército de Flandes. Pero será el padre, Juan de llarraza, el que establezca fuertes vínculos con la oligarquía de Álava, ya que a través de su matrimonio con Apolonia Ladrón de Guevara entró a formar parte del círculo político de esta familia, pues el padre de su esposa, Juan Ladrón de Guevara, fue Procurador General de la Junta de Caballeros Hijosdalgos de Elorriaga, y dos de sus cuñados obtuvieron empleos importantes: Luis Ladrón de Guevara, colegial en el Colegio mayor del Arzobispo de Salamanca fue canónigo lectoral de la Catedral de Zamora; el otro, Diego Ladrón de Guevara, fue diputado de la Junta Particular de Álava y comisario para el recibimiento de la infanta de Castilla y Delfina de Francia. Un hijo de este último, Juan Antonio Ladrón de Guevara, fue colegial también en el Colegio del Arzobispo de Salamanca y alcalde del crimen en la Chancillería de Valladolid, aunque su muerte prematura abortó una carrera prometedo$\mathrm{ra}^{23}$. El segundo matrimonio del padre, ahora con Apolonia de Oro, celebrado el 8 de julio de 1743, y del que nació Santiago Antonio de Ilarraza, debió de ser, sin embargo, de menor alcurnia, puesto que nada dicen los testigos sobre la nobleza del linaje materno ni sobre los puestos que la familia había ocupado en el gobierno local y provincial.

En cualquier caso, los vínculos familiares del primer matrimonio serán decisivos para la promoción de los hijos habidos en el segundo matrimo-

21 Sobre este aspecto, J. CARo BAROJA, La hora navarra del XVIII (Personas, familias, negocios e ideas), Pamplona, 1969.

22 Así consta en el expediente de José Benito de llarraza (AGP, EP, Caja 7829/6). 
nio. Porque Santiago Antonio de llarraza se beneficiará, sin duda, de la influencia que tiene en la Corte su hermanastro José Benito de llarraza, nacido el 23 de marzo de 1729, Capellán de honor en 1763, predicador supernumerario de $\mathrm{S}$. M en 1766 y de número en 1782 a petición del $\mathrm{Pa-}$ triarca, quien así lo solicita al rey por ser el predicador supernumerario más antiguo, capellán en los reales oratorios, dignidad de penitenciario de la Capilla, confesor de la Princesa de Asturias y finalmente Cura de Palacio, lo que significa quizás el punto culminante de su carrera -otro hermano de éste, fray Benardino de Santo Tomás, fue lector de Teología en su Orden-. Pero Santiago Antonio de llarraza no es el único miembro de la familia que se beneficia de las relaciones adquiridas en la Casa Real por su hermanastro, ya que, siguiendo las reglas establecidas por el sistema endogámico, presente en todos los sectores de la sociedad del Antiguo Régimen y uno de los pilares básicos en los que se apoya la carrera y el ascenso social del individuo, otros familiares logran insertarse en las dependencias del Palacio Real. Así, en los años 1776 y 1783 encontramos a José Antonio de llarraza, primo de José Benito y de Santiago Antonio, como Contador y Tesorero del Buen Retiro 24 , cargo que es ocupado a su fallecimiento por Cristóbal de llarraza, hermano de Santiago Antonio y hermanastro de José Benito 25. Sabemos asimismo que María Isabel de llarraza, hermana de Santiago Antonio, contrae nupcias con Marcos Ortiz, Agente Fiscal del Consejo de Castilla, y que su sobrina María Isabel de Anda e llarraza, enlaza con el conde de Montefuerte y una hermana de esta, Leocadia de Anda e llarraza de Olaeta, se casa a su vez con José Victoriano de Olaeta, alcalde del crimen de la real Chancillería de Valladolid, ampliando así el círculo endogámico de la familia a otros linajes y perpetuándolo en los primeros años del siglo XIX ${ }^{26}$.

Por otro lado, constatamos, cuando echamos un vistazo a los cargos que ocupan en la sociedad los testigos en el proceso de limpieza de sangre, que todos ellos provienen de determinadas capas de la sociedad. Ya hemos mencionado los cargos eclesiásticos y administrativos de algunos testigos que intervienen en las pruebas de Santiago Antonio de llarraza. En el proceso de José Benito de llarraza, acaecido veinte años antes, sucede lo mismos, pues declaran, entre otros, Pedro García de Mendoza y Simón de Arcinaga, regidores del lugar de Ariñiz; Joaquín Hurtado de

23 AGP, EP, Caja 7829/6. Expediente de José Benito de llarraza

24 AGP, EP, Caja 11562/49.

25 AGP.Exp.Pers. C2523/8

26 Estos últimos datos en el testamento que Santiago Antonio de llarraza otorga en 31 de marzo de 1826 ante Pedro de Guinea (AGP, EP, C 7790/5). 
Mendoza, del Consejo de Hacienda, Oidor de la Real Chancillería de Valladolid, quien es además señor de Martesola y de la Hermandad de los Huetos; José Manuel de Esquivel y Rivas, marqués de Legarda (conviene recordar que también declara en las pruebas de Santiago Antonio), del Consejo de Hacienda, Juez subdelegado de las Rentas del Tabaco y Salinas de Cantabria y Gobernador de sus Aduanas; y Bartolomé José de Urbina y Zurbano, marqués de la Alameda. Solidaridades tanto profesionales como regionales, pues no se debe ignorar que en este tipo de relaciones desempeña un destacado papel el lugar de nacimiento, y no nos referimos a que entre los testigos aparezcan varios vecinos de la localidad en la que había nacido el pretendiente y vivido sus antepasados, pues nadie mejor que ellos para informar sobre su nobleza y su limpieza de sangre, sino al hecho de que algunos de los testigos, que ya ejercen algún puesto importante en la Corte, y que intervienen en los interrogatorios, son oriundos del lugar de origen del candidato o de su provincia, reforzando asi los vínculos geográficos 0 , si se quiere, de la patria común derivada del lugar de nacimiento, tanto o más fuertes que los lazos de la amistad. Un fenómeno que se aprecia nítidamente con los capellanes de honor vasco-navarros y desde comienzos del siglo XVIII, pues el capellán de honor Francisco Bentilac y Oses testifica a favor de Juan Fernández de Mendivil y éste a favor de Juan Aristia y Elizacoechea, quien a su vez testifica en 1743 en las pruebas de Pedro de Laurnaga, el cual años antes, en 1739, habia testificado en las de Juan Aristia y Elizacoechea, de quien habia sido compañero en el Colegio de Lugo de la Universidad de Alcalá de Henares. Y es que, como señala J. I. Imicoz, los vínculos que vertebran la propia sociedad de origen, ya sean de familia, parentesco, vecindad, amistad o paisanaje, son los que contribuyen a explicar estas solidaridades entre los capellanes de honor navarro, pues lo frecuente era que una vez instalados en Madrid ayudaran a hacer carrera a sus parientes y paisanos 27.

Si la posición política de la familia paterna era notable, su fortuna no le andaba a la zaga. Desafortunadamente, el testamento del padre que figura en las pruebas de Santiago Antonio de llarraza, fechado el 16 de marzo de 1761, no aporta demasiada información al respecto, porque ni siquiera se indican expresamente las misas que deben darse por la salvación de su alma, ya que lo deja al criterio de los albaceas, su esposa y su hijo José Benito de llarraza. Tampoco sabemos cuál fue su fortuna ni

27 J. M. Imicoz, «De la comunidad a la nación: élites locales, carreras y redes sociales en la España moderna», en Elites,poder y red social: las élites del País Vasco y Navarra en la Edad Moderna, Bilbao, 1996, pp 193-210. 
como se distribuyó entre sus herederos, sus hijos José Benito de llarraza y fray Benardino de Santo Tomás, habidos en su primer matrimonio, y María Isabel, María Jesús, religiosa profesa, María Martina, Cristóbal Antonio y Santiago Antonio, habidos en segundas nupcias, aunque en el testamento se dice que son sus herederos universales exceptuados los religiosos «que hicieron renuncia y voto de pobreza» 28 . Algo más explícito es el testamento de la madre de Santiago Antonio de llarraza fechado el 5 de marzo de 1773 -fallece el 25 de junio de 1774-, ante Tomás Vélez de Mendizábal y Guevara, escribano real, ya que en el, aparte de dejar establecido que desea ser amortajada con el hábito franciscano, como su marido, lo cual refleja una vez más las costumbres arraigadas entre las clases altas de la época, ordena ser enterrada en la capilla del altar de la iglesia parroquial, todo un signo de la importancia social de la familia, ya que es una de las zonas más caras de enterramiento ${ }^{29}$, con asistencia de diez sacerdotes, oficiándose sobre su sepultura una misa de cuerpo presente y un novenario de misas con responso y pan añal durante un año, así como función de honras y cuantas misas más establecieran sus testamentarios, en calidad de los cuales deja a su hija Maria Isabel y a José Benito de llarraza, hijo mayor de su marido, habido de su primer matrimonio, aparte de fundar una misa de aniversario que se celebrará cada año con asistencia del cabildo de la iglesia y que se sufragará con una limosna que deja de cuatro reales «a cuya seguridad apensionará una heredad raíz detraída de cinco cargas" 30 .

\section{EL OFICIO DE CAPELLÁN DE HONOR: FUNCIONES, SALARIOS Y EMOLUMENTOS}

Según las constituciones de Juan II de Castilla, remodeladas en los siglos XVI y XVII y últimamente en 1757, el Patriarca o Capellán Mayor estaba asistido por una Junta de Capellanes integrada por el Receptor 0 Presidente, el Juez de la Capilla, el Cura de Palacio y dos o más Doctora-

28 AGP, EP, Caja 7790/5. Compulsa de 28 de septiembre de 1772 firmada por Nicolás Martínez de Armentia.

29 Ph. ARIES, El hombre ante la muerte, Madrid, 1983; T. EgIDO, «La religiosidad colectiva de los vallisoletanos", Valladolid en el siglo XVIII, tomo V de la Historia de Valladolid, Valladolid, 1984, p. 229; M." J de la Pascua, Vivir la muerte en el Cádiz del Setecientos (1675-1801), Cádiz, 1990, p. 186.

30 Compulsa del testamento de Apolonia de Oro Umendia, sin fecha, realizado por Nicolés Martínez de Armendia (AGP, EP, Caja 7790/5). 
les, la cual se reuniría al menos una vez al mes para discutir de los asuntos de gobierno de la Real Capilla ${ }^{31}$. Al margen de esta Junta, por el artículo diez y siguientes de las constituciones de 1757 se regulan con exactitud tanto la composición como las funciones que ha de tener el Banco de Capellanes. Este, se dice, será una comunidad de sujetos condecorados, dignos y beneméritos de la honra que se les hace y servirá a los Reyes en su Capilla y Oratorios, asistiendo a los oficios y funciones de la capilla en los días que se establezca. El Banco de Capellanes estará formado por cuarenta capellanes, veintiséis del llamado Banco de Castilla y catorce reservados para caballeros de Ordenes Militares: cuatro para la de Santiago, tres para la de Alcántara, tres para la de Calatrava, dos para la de Montesa y dos para la de San Juan. A los Capellanes de honor les corresponde además intervenir en las pruebas de nobleza y limpieza de sangre de los aspirantes a una capellanía de honor, interviniendo como jueces informantes o en las comisiones designadas para aprobar las pesquisas realizadas y la idoneidad del candidato. Finalmente, algunos capellanes tienen designados cometidos especiales, como el Receptor, el Juez, el Cura de Palacio, el Fiscal y el Maestro de Ceremonias.

El Receptor, que será el decano y presidente del Banco y Coro, y que, subordinado al Capellán Mayor, está obligado a asistir siempre a las funciones de Capilla para asistir al Prelado en todos los actos que ejerza en ella: servirle el agua bendita, llevar el incienso para ser bendecido, señalar los ministros para los pontificales y los capellanes de honor que habrán de velar en las cuarenta horas y en los «descubiertos de la Capilla" y formar, asimismo, los sermones de Adviento y Cuaresma un mes antes y entregarla al Patriarca. A su cuidado estará también supervisar las misas que se han de decir en los Oratorios Reales, avisando la hora a los Capellanes que tengan este encargo, y tomar el Juramento y la toma de posesión de los nuevos Capellanes y Predicadores del rey, con orden del Capellán Mayor. Función ésta que podrá realizar también, por diferentes motivos, el Mayordomo Mayor de Palacio. Habrán de tener en su casa los libros y hacer los asientos correspondientes a los nuevos Sumilleres de Cortina, así como a los Capellanes y Predicadores, una vez jurados los cargos. Cuidará, por último de que cada ministro cumpla con sus funciones y de cualquier alteración o disturbio dará cumplida cuenta al capellán Mayor.

El Juez de la Capilla es el encargado de intervenir en todas las causas, tanto civiles como eclesiásticas, de los ministros de la Capilla y feli-

31 AGP, Sección Administrativa, leg 1133. Constituciones de la Real Capilla de los Reyes Católicos, 1757. Artículo 2. 
greses de la Parroquia de Palacio. Tendrá que ser un capellán de honor con grado, ciencia y prudencia. Como los demás cargos es propuesto por el Patriarca al Rey quien le nombra. Según expone el Patriarca con motivo de la propuesta de nombramiento de Domingo de la Espriella para ocupar el cargo de juez, este empleo es de suma importancia, ya que tiene mucha "concurrencia con el Capellán mayor y capellanes de honor para la aprobación de las informaciones de predicadores y capellanes, como para otras providencias económicas y gubernativas. Tiene asimismo lugar determinado de asiento en la Capilla, goza de gajes, distribuciones y emolumentos. Si no fuera capellán los otros capellanes dudarían de su derecho a recibir ciertas distribuciones y gajes" 32 .

El fiscal de la Capilla Real, propuesto también al monarca por el Capellán Mayor, deberá ser capellán de honor y su función primordial será la de cuidar de todo lo perteneciente a la Capilla y al Tribunal eclesiástico de ella, así como de las tareas que en este sentido le encomiende el Capellán Mayor, a quien tendrá que rendir cuentas de todo exceso y desorden por parte de cualquier individuo de la Capilla y de su jurisdicción 33 .

El cura de palacio es propuesto al rey por el Capellán mayor de entre los capellanes de honor y entre sus cometidos se encuentra el de ser cura y confesor de palacio -no es confesor real-, debiendo ser persona entendida en los sacramentos y en el cuidado espiritual, pues atenderá a todas las personas que vivieren en Palacio y en las casas adyacentes sujetas a su jurisdicción. Informará al Capellán Mayor de lo que convenga saber para el buen gobierno de los parroquianos así como de quienes no cumplan con el precepto anual ${ }^{34}$. Como el cura de palacio no puede por sí solo confesar al personal de palacio, se autoriza al capellán mayor para que pueda otorgar licencia para confesar a los capellanes de honor y a los religiosos de las ordenes que fuesen necesarios, quienes así lo harán en la capilla real y en el oratorio de las damas, bien entendido que las licencias se otorgarán por escrito y nunca demasiadas para no crear confusión 35. Del mismo modo, el Capellán mayor podrá nombrar confesores de familia para las personas extranjeras que hubiere en la Corte, especialmente en las Jornadas Reales, con el único requisito de que sepan francés, italiano o alemán 36 .

32 lbidem, artículo 4.

33 Ibidem, artículo 5 .

34 Ibidem, artículo 6.

35 ibidem, artículo 8.

36 lbidem, artículo 7. 
El Maestro de Ceremonias es el capellán a cuyo cargo están las ceremonias de altar, coro y Capilla. Estará asistido por un teniente o Segundo Maestro de ceremonias. Tendrá que ser un capellán versado en rúbricas, ceremonias generales, ceremonial romano y ceremonial de la real Capilla y Palacio. Dicen expresamente las constituciones de 1757 que tanto el Primer Maestro ce Ceremonias como el segundo serán a partir de ahora capellanes del Banco de Capellanes y que en ausencia del primero asistirá siempre el segundo a las funciones de Capilla. El Maestro de Ceremonias tendrá especial cuidado en que los oficios se hagan de acuerdo con el ritual romano y no se altere nada sin expresa orden del capellán mayor. El Maestro de Ceremonias tendrá que entregar el «añalejo» u orden de rezo de la capilla al Capellán Mayor para hacerlo registrar y que salga "sin defecto alguno" 37 . En los Oficios de Pontifical estará el maestro de Ceremonias (o los dos maestros), para asistir al Capellán Mayor y para corregir "con alguna seña y con disimulo" si alguno de los asistentes tiene algún fallo. Advertirá a los capellanes de Altar la forma de celebrar las misas y hacer los demás oficios. Es otro de sus cometidos examinar de ceremonial a todos los Capellanes de Altar, y sin su aprobación no podrán empezar a servir su empleo. Cada primero de mes, el Maestro pondrá una tabla en la sacristía de la Capilla en que se anoten las fiestas de aquel mes, días en que además de misa mayor habrá en la $\mathrm{Ca}$ pilla Vísperas, Completas, Maitines, Laudes y Horas Menores.

¿Cuáles eran los ingresos de los Capellanes de Honor?. Según se establece en la Planta de 1802 los capellanes de honor recibirán en concepto de distribuciones 4.000 reales de vellón al año y aquellos que asistiesen a las Jornadas de los Reales Sitios veintidós reales diarios en concepto de mesilla o ayuda de costa. Sin embargo, algunos capellanes, por los cargos y dignidades que gozaban en la Capilla, tenían asignadas también otras retribuciones. En efecto, por sus oficios, el Receptor percibía 24.000 reales, el Juez, 27.000, el Cura de Palacio, 24.000, los Doctorales, 8.000 cada uno, los Penitenciarios, 8.000 cada uno, el Fiscal, 8.250, el Primer Maestro de Ceremonias, 8.800, el Segundo Maestro de Ceremonias, 3.300, y otros seis capellanes, por sus méritos, 6.000 reales cada uno. Finalmente aquellos capellanes que eran al mismo tiempo predicadores del rey percibian 2.500 reales al año 38 . Así, pues, se puede decir que a finales del siglo XVIII y comienzos del siglo XIX el personal eclesiástico de la Capilla Real había conseguido tener una retribución fija

37 Ibidem, artículo 86.

38 AGP, Sección Histórica, Caja 54. Lista de Todos los Individuos de la real capilla que hacen algunas servidumbres al rey...1802. 
y algunos capellanes de honor disfrutar de unos ingresos ciertamente considerables, próximos a los que obtenían otros cargos eclesiásticos de alto rango como se comprueba comparando los salarios de unos y otros, ya que en los años 1785 y 1787 cerca de los dos tercios de los dignidades de las Iglesias Catedrales obtenían unas rentas que oscilaban entre los 6.000 y los 20.000 reales anuales, mientras que el 80 por ciento de los canónigos eran retribuidos con cantidades comprendidas entre los 6.000 y los 20.000 reales al año 39 .

\section{LA PROMOCIÓN DEL CAPELLÁN DE HONOR. EL JUEGO DE LAS CLIENTELAS}

Pero si importante era el salario no menos lo eran los honores. Todos los religiosos que acaban ocupando una capellanía provienen de éste grupo de nobles hidalgos ó bien de la baja aristocracia. Se utiliza la carrera eclesiástica, así como la militar para el ascenso social, dentro de la cual destacan de manera especial los cargos en la Real Capilla. Es este canal de obtención de posición social y honores doblemente deseado: por un lado dispone para situarse cerca del rey y los mas altos círculos de poder, y por otra parte sirve de catapulta para alcanzar aún mas importantes preeminencias. No olvidemos que gran parte de los capellanes de honor alcanzan mitras episcopales y alguno de ellos incluso capelo cardenalicio. Como escribe C. Hermann, el rango de los Capellanes de Honor era muy superior a sus haberes. Esto, que se comprueba por la posición que ocupaban en las celebraciones religiosas en la Capilla Real de Palacio, en el lado del Evangelio, detrás de los cardenales y embajadores -en el lado de la Epístola se colocaban los obispos--. Por otra parte, su proximidad a la familia real les facilitaba la posibilidad de obtener mejores empleos. Así, por ejemplo, José Ilarraza Ladrón de Guevara, alcanzará la merced de ser nombrado confesor de la princesa de Asturias ${ }^{40}$, 10 mismo que Rafael Múzquiz y Aldunate, que es designado en 1791 por Carlos IV como confesor de la reina y en 1794 abad de la Colegiata del Real Sitio de San Ildefonso, para posteriormente ser nombrado obispo de Seleucia y elevado a la mitra de Ávila, en cuya diócesis permanecerá entre 1799 y 1801 , siendo posteriormente promovido a la sede arzobispal de Santiago 298.

C. HermanN, L'Eglise d'Espagne sous le patronage royal (1476-1834), Madrid, 1988, pp.

40 AGP, EP, C 7829/6. 
de Compostela, donde fallece en 1821, obteniendo los dos el título de Caballero pensionado de la Orden de Carlos III ${ }^{41}$.

No parece ser este el caso de Santiago Antonio de llarraza y Oro cuya carrera, sin duda prometedora en sus inicios, ya que es nombrado Primer Maestro de Ceremonias, se ve truncada en 1791 al ser expulsado de la Capilla Real por el monarca tras haber causado su indignación debido, según palabras textuales del propio llarraza y Oro, a «un chisme producido por un Ayuda de Oratorio, como le constan al Receptor de la Capilla, Cura de Palacio y demás compañeros de su tiempo» 42. Pero apartado de la Capilla, lo cierto es que en 1800 es nombrado para el beneficio de la Iglesia de Hellín, no obstante disfrutar de otro en la Catedral de Sevilla, con lo que en cierto modo la Corona, quizás por intercesión del Patriarca, como así lo había solicitado el 9 de Noviembre de 1795, demuestra haberle perdonado. Quien parece tenerle en su estima es el príncipe de Asturias, a quien acompaña a Vitoria y a quien da la misa en sus alojamientos, sirviéndole además de Sumiller de Cortina en los Oficios de Semana Santa celebrados en la colegiata de dicha ciudad. Esto explica que en 1814 Fernando VII, atendiendo a sus súplicas, le reintegre a su capellanía con su antigüedad incluyendo la Maestría de Ceremonias, en lo que sin duda influyó el informe que a petición del monarca redacta el Receptor de la Capilla en 10 de Junio de ese mismo año y del que nada se desprende en demérito de Santiago Antonio de llarraza, sino todo lo contrario, ya que considera que su "conducta patriótica ha sido la mejor, habiendo dado pruebas de amor y adhesión a S. M.", y que todo el escándalo se redujo a que el bulo levantado por el Ayuda de Oratorio fue apoyado por personas más condecoradas. El Receptor en su carta insta a que se le reponga en su cargo, dado que la Maestría de Ceremonias está vacante en ese momento y teniendo en cuenta la mucha instrucción que el interesado tiene en el cargo ${ }^{43}$.

A partir de este momento, su carrera vuelve a experimentar un signo favorable. En efecto, en 1817 se le concede la cruz de caballero pensionado de Carlos III por promoción a la Gran Cruz de Francisco Yánez Isahamonde, satisfaciendo el monarca su petición de 1816, en la que solicitaba recibir la que había quedado vacante a la muerte de Antonio Borruel,

41 AGP, EP, C 7840/9. Ver para R. MúzQulz, Diccionario de Historia Eclesiástica de España, Madrid, 1972.

42 AGP, EP, C 4790/5. Memorial dirigido al rey por Cristóbal Antonio de llarraza en nombre del capellán de honor fecha el 4 de Junio de 1814.

43 AGP, EP, C 4790/5. Carta del Duque de San Carlos, Mayordomo Mayor del Rey, de fecha 26 de Junio de 1814, enviada al Patriarca notificándole el nombramiento. 
alegando que otros capellanes más modernos que él en sus cargos gozaban ya de este honor, y que no consigue entonces por estar reservada a otro individuo y el Patriarca a la espera de que se le avise la vacante por parte de la Secretaría de Estado y del Despacho para poder proveerla por ser ésta de las asignadas al Patriarca para su provisión como Gran Canciller de la Orden de Carlos III. Para entonces, sin embargo, la salud de Santiago Antonio de llarraza comenzaba a deteriorarse. En 1817, Andrés de Aransay, Receptor de la Capilla, eleva una propuesta al monarca para que se le reemplace al frente de la Maestría de Ceremonias a causa de sus muchos años y de encontrarse enfermo. Dos años más tarde, Santiago Antonio de llarraza solicita por la misma causa que el rey le excuse de decir misa en los oratorios reales, dispensa que obtiene el 12 de Enero de 1819. Con todo, aún viviría varios años más y de manera activa, asistiendo a las funciones religiosas de la Capilla, si bien en 1824 envía un nuevo memorial al Patriarca a fin de que se le conceda cédula de preeminencia o dispensa de acudir a los actos religiosos excepto cuando la salud se lo permita, a lo que Fernando VII accede tras la oportuna consulta al Capellán Mayor quien resalta en su informe favorable que Santiago de llarraza a estado al servicio real durante casi cuarenta años. No sólo se le concede la citada cédula, sino que posteriormente se le autoriza abandonar la Corte y trasladarse a Alava para, desde allí, poder pasar a los baños de Cestona, en la provincia de Guipúzcoa, a tomar las aguas.

Pese a este viaje su salud no debió de mejorar, puesto que el 31 de marzo de 1826 redacta su testamento ante Pedro de Guinea, escribano de S. M. En él nombra por testamentarios a Bartolomé García Marín, capellán de honor y segundo Maestro de ceremonias, a José Victoriano de Olaeta y a Julián Segundo de Ortega, oficial de la Secretaria de la Cámara y del Real Patronato, quienes deberán observar fielmente sus disposiciones: que se le entierre en el cementerio de la Puerta de Toledo, donde se comprará una sepultura de nicho valorada en 440 reales, y que se le recen mil misas por su alma, con limosna de a ocho reales cada una. Finalmente, deja por herederas universales a sus sobrinas María Isabel de Anda e llarraza, viuda del conde de Montefuerte, y Leocadia de Anda e Ilarraza, casada con José Victoriano de Olaeta, alcalde del crimen de la Chancillería de Valladolid. Empero, la muerte se resistía a liberar su alma, pues entre la fecha de su testamento y la de su óbito transcurren aún más de año y medio, ya que su fallecimiento tiene lugar el 24 de septiembre de 1827, a la edad de setenta y dos años, siendo registrada la partida de su defunción por Martín Beltrán de Caicedo el 21 de noviembre de 1827. 